\title{
Analysis of a Slab and Slab Heater Cover in a Compact Endless Cast and Rolling Mill Process Using Finite Element Methods
}

\author{
Jong Won Baek ${ }^{1}$, Joo Won Oh${ }^{1}$, Jae-Sook Chung ${ }^{2}$, Yong-Seok Cho ${ }^{2}$, and Seong Jin Park ${ }^{1, *}$ \\ ${ }^{1}$ Department of Mechanical Engineering, Pohang University of Science and Technology (POSTECH), \\ Pohang 37673, Republic of Korea \\ ${ }^{2}$ CEM Project Global POIST Project Department, POSCO Gwangyang Works, Gwangyang 57807, Republic of Korea
}

\begin{abstract}
Compact Endless cast and rolling Mill (CEM) processes were developed and used to fabricate steel products such as steel slabs. However, the coiling furnace in this process was very expensive, so a new layout was suggested. As the coiling furnace was removed, the interval among the slab heaters had to be increased. This led to a temperature drop in the slab. The temperature distribution of the slab impacts quality, so new layout was developed. This paper presents a Finite Element Method (FEM) simulation of thermal behavior in the slab employing slab heater covers. All of the simulation results were verified by comparing them with experimental results. The slab moving distance at which the temperature was saturated during the process was determined to consider the steady-state and analyze the temperature distribution of the slab and slab heater. Those results revealed that the efficiency of heat conservation increased by more than $50 \%$ using the slab heater cover. Finally, a sensitivity analysis of the slab heater cover was conducted with respect to the cover design. The effects of insulator thickness, the gap distance between the slab and cover, and material parameters such as density, and specific heat were investigated to optimize the design of the slab heater cover to produce the best quality slab.
\end{abstract}

(Received November 6, 2018; Accepted November 13, 2018)

Keywords: compact endless cast and rolling mill (CEM), FEM simulation, sensitivity analysis

\section{INTRODUCTION}

Steel is one of the most important materials for engineering and manufacturing. Generally, the following four processes are required to fabricate a steel product: smelting, steel making, continuous casting, and hot rolling. Continuous casting and hot rolling processes are the most widely used. Both have the advantages of shape complexity, mass production, and cost effectiveness [1,2].

However, there are some discontinuities between the conventional continuous casting and the hot rolling processes. The discontinuities may decrease product quality such as, surface roughness, and homogeneity. When using a hot rolling mill, producing thin steel plates is very difficult and results in low surface quality and low

- 백종원·오주원: 박사과정, 정제숙·조용석: 연구원, 박성진: 교수

*Corresponding Author: Seong Jin Park

[Tel: +82-54-279-2182, E-mail: sjpark87@postech.ac.kr]

Copyright (C) The Korean Institute of Metals and Materials strength, because of surface oxidation due to the temperature drop.

Therefore, a new process, called the Compact Endless cast and rolling Mill (CEM) was developed by Pohang Iron \& Steel Company (POSCO) [3]. CEM is an advanced process technology that combines continuous casting and the hot rolling process, and it has many advantages. CEM processes can make mass production with high quality slabs. Additionally, thin products which are very difficult to produce by hot-rolling can now be easily manufactured. With the proposed method, it is possible to maintain the uniform high quality of hot-rolled products, which were once difficult to fabricate using conventional hot-rolling or casting. Figure 1 shows the layout of the CEM process.

First, the hot slab is moved from the continuous caster and passed through the slab heater to reheat for temperature recovery and homogenization. Next, the slab is moved into the coiling furnace and finishing mill to conduct coiling and adjust sizing. However, the coiling furnace is a very 


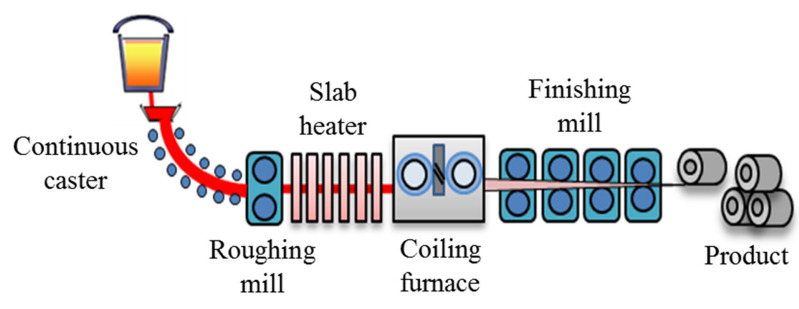

Fig. 1. Layout of CEM

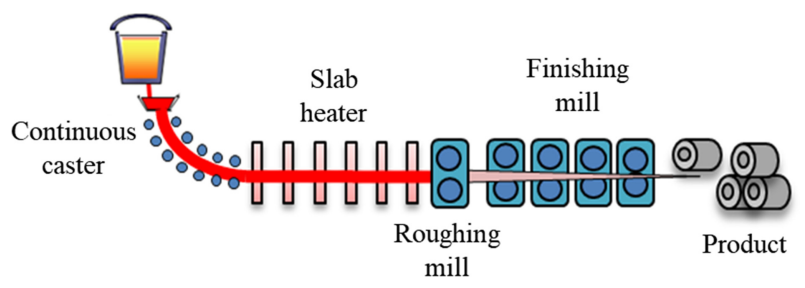

Fig. 2. New suggested layout of CEM.

expensive device and has high maintenance costs. Therefore, the new proposed layout as shown in Fig. 2 can overcome this drawback.

In the new layout, the slab passes through the slab heaters and is shaped in the finishing mill. The gap between the slab heaters was increased and not covered, so the slab temperature rapidly dropped when the slab was passed through the slab heater. In the steel-fabrication process, the temperature distribution is the most important parameter determining slab quality [4-11]. Temperature distribution also affects the kinetic and kinematic parameters, such as stress, strain, and deformation, which are directly related to quality $[12,13]$. Moreover, these effects impact the hardness or ductility of a slab $[14,15]$. Variation of temperature can be decreased by using a slab heater cover between slab heaters.

In this study, thermal and structural analysis in the slab with slab heater covers were conducted for new the layout CEM process. Simulation results were verified by comparing them the experimental results. A sensitivity analysis of the slab heater cover was carried out to determine the greatest influence on the slab temperature and deformation.

\section{THEORY}

In the CEM process, heat transfer from the heater to the slab depends mainly on radiation, because of the high temperature difference. Heat conduction is the dominant heat transfer inside the slab and the slab heater. The heat transfer by the radiation can be determined using equation (1): [16]

$$
\sum_{i=1}^{N}\left(\frac{\delta_{j i}}{\varepsilon_{i}}-F_{j i} \frac{1-\varepsilon_{i}}{\varepsilon_{i}}\right) \frac{1}{A_{i}} Q_{i}=\sum_{i=1}^{N}\left(\delta_{j i}-F_{j i}\right) \sigma T_{i}^{4}
$$

where $N$ is the number of radiating surfaces, $\delta_{j i}$ is the Kronecker delta, $\varepsilon_{i}$ is the effective emissivity of the surface $i, A_{i}$ is the area of surface $i, Q_{i}$ is the energy loss of surface $i, \sigma$ is the Stefan-Boltzmann constant, and $T_{i}$ is the absolute temperature of surface $i . F_{j i}$ contains the radiation view factors, which are defined as the blocked fraction of total radiant energy by the surface $i$, as shown in Fig. 3 and expressed by equation (2):

$$
F_{j i}=\frac{1}{A_{j}} \int_{A_{j}} \int_{A_{i}} \frac{\cos \theta_{j} \cos \theta_{i}}{\pi r^{2}} d\left(A_{i}\right) d\left(A_{j}\right)
$$

where $A_{i}$ and $A_{j}$ are the areas of surfaces $i$ and $j$ respectively, $r$ is the distance between differential surfaces $i$ and $j, \theta_{i}$ and $\theta_{j}$ are the angles between normal vectors, $N_{i}$ and $N_{j}$, and the radius line to surface $d\left(A_{i}\right)$ and $d\left(A_{j}\right)$, respectively.

Heat transfer by conduction can be described as equation (3) $[17]:$

$$
\rho c \frac{\partial T}{\partial t}=k\left(\frac{\partial^{2} T}{\partial x^{2}}+\frac{\partial^{2} T}{\partial y^{2}}+\frac{\partial^{2} T}{\partial z^{2}}\right)+E_{w}
$$

where $\rho$ is the material density, $c$ is the specific heat, $k$ is the thermal conductivity, and $E_{w}$ is the energy input due to mechanical work. $E_{w}$ is zero because CEM process receives no external energy input.

Using the temperature distribution obtained from equations

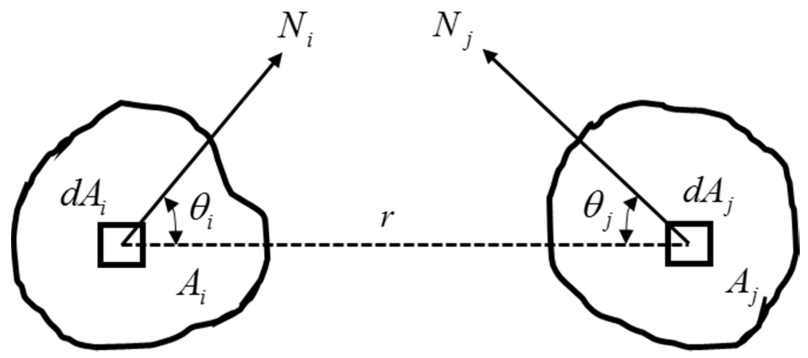

Fig. 3. View factors with parameters 
(1) to (3), the thermal stress can be calculated by equation (4): [18]

$$
\sigma_{\text {thermal }}=E \alpha\left(T-T_{0}\right)
$$

where $E$ is Young's modulus, $\alpha$ is the thermal expansion coefficient, $T$ is the current temperature, and $T_{0}$ is the initial temperature.

\section{GEOMETRY AND MATERIAL PROPERTIES}

Figure 4 shows the slab heater cover design for the CEM process. The slab heater cover consists of three parts: the front cover, the insulator and the external cover. The slab passes through the slab heater cover. SS400 was used for the front and external covers, and Ceramol\#150 was used as an insulator. The slab was provided by POSCO. The mechanical and thermal properties of the slab, cover and insulator are summarized in Table 1.

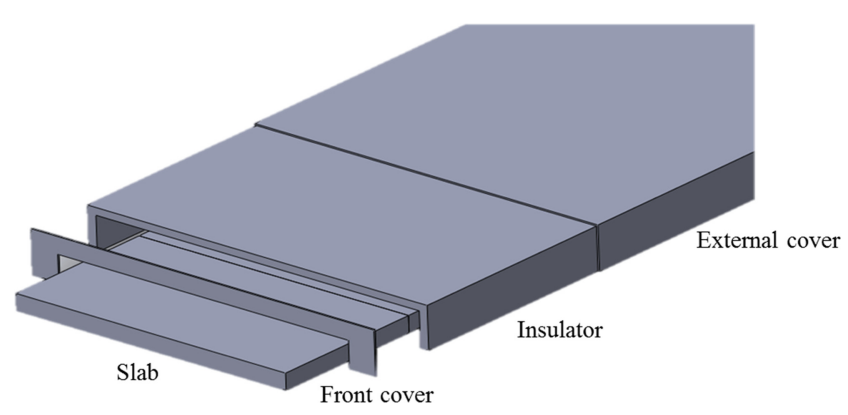

Fig. 4. Layout of slab heater cover

\section{RESULTS AND DISCUSSION}

\subsection{Simulation verification}

A cooling experiment was conducted to verify the simulation. A schematic diagram of the experiment is shown in Fig. 5. The cooling time was 30 seconds, and the temperatures at the surface, and the center of the slab were measured by thermocouples. The average temperature was obtained by calculating the temperature of each thermocouple. The results of the cooling experiment are shown in Table 2.

Comparing the experimental and simulation results (Table 2, 3 and Fig. 6), the surface temperature differences between the start and the end were respectively $53^{\circ} \mathrm{C}$ and $55.3^{\circ} \mathrm{C}$. The average temperature differences were $16^{\circ} \mathrm{C}$ and $12.8^{\circ} \mathrm{C}$, and the center temperature differences were $11^{\circ} \mathrm{C}$ and $9.4^{\circ} \mathrm{C}$, respectively. The errors between the experimental and simulation results were all within $3{ }^{\circ} \mathrm{C}$. Thus, the simulation was verified.

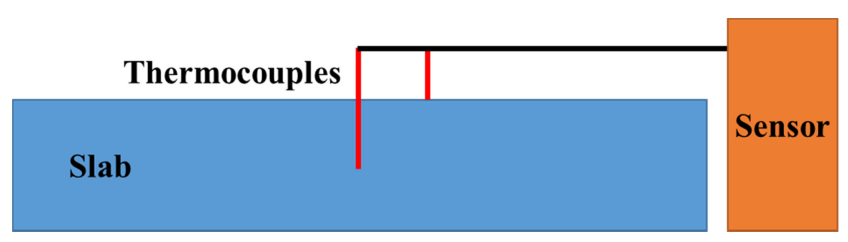

Fig. 5. Schematic diagram of the cooling experiment

Table 2. Results of cooling experiment

\begin{tabular}{cccc}
\hline & Surface & Average & Center \\
\hline Start temperature $\left({ }^{\circ} \mathrm{C}\right)$ & 1141 & 1169 & 1193 \\
\hline Final temperature $\left({ }^{\circ} \mathrm{C}\right)$ & 1088 & 1153 & 1182 \\
\hline Difference $\left({ }^{\circ} \mathrm{C}\right)$ & 53 & 16 & 11 \\
\hline
\end{tabular}

Table 3. Results of cooling simulation

\begin{tabular}{cccc}
\hline & Surface & Average & Center \\
\hline Start temperature $\left({ }^{\circ} \mathrm{C}\right)$ & 1141 & 1169 & 1193 \\
\hline Final temperature $\left({ }^{\circ} \mathrm{C}\right)$ & 1085.7 & 1156.2 & 1183.6 \\
\hline Difference $\left({ }^{\circ} \mathrm{C}\right)$ & 55.3 & 12.8 & 9.4 \\
\hline
\end{tabular}

Table 1. Material properties of slab heater cover parts

\begin{tabular}{cccccccc}
\hline & \multicolumn{3}{c}{ Mechanical properties } & \multicolumn{3}{c}{ Thermal properties } \\
\cline { 2 - 9 } & $\begin{array}{c}\text { Thermal } \\
\text { expansion } \\
\text { coefficient } \\
\left(10^{-6 \circ} \mathrm{C}\right)\end{array}$ & $\begin{array}{c}\text { Young's } \\
\text { modulus } \\
(\mathrm{GPa})\end{array}$ & Poisson's ratio & $\begin{array}{c}\text { Thermal } \\
\text { conductivity } \\
\left(\mathrm{W} / \mathrm{m}^{\circ} \mathrm{C}\right)\end{array}$ & $\begin{array}{c}\text { Heat } \\
\text { Capacity } \\
\left(\mathrm{J} / \mathrm{kg}^{\circ} \mathrm{C}\right)\end{array}$ & $\begin{array}{c}\text { Density } \\
\left(\mathrm{kg} / \mathrm{m}^{3}\right)\end{array}$ & Emissivity \\
\hline Cover & 11 & 210 & 0.26 & 50 & 480 & 7850 & 0.57 \\
\hline Insulator & 5 & 39.1 & 0.27 & 0.279 & 1046 & 0.90 & 1160 \\
\hline Slab & 12.6 & 200 & 0.27 & 36 & 800 & 7872 & 0.83 \\
\hline
\end{tabular}




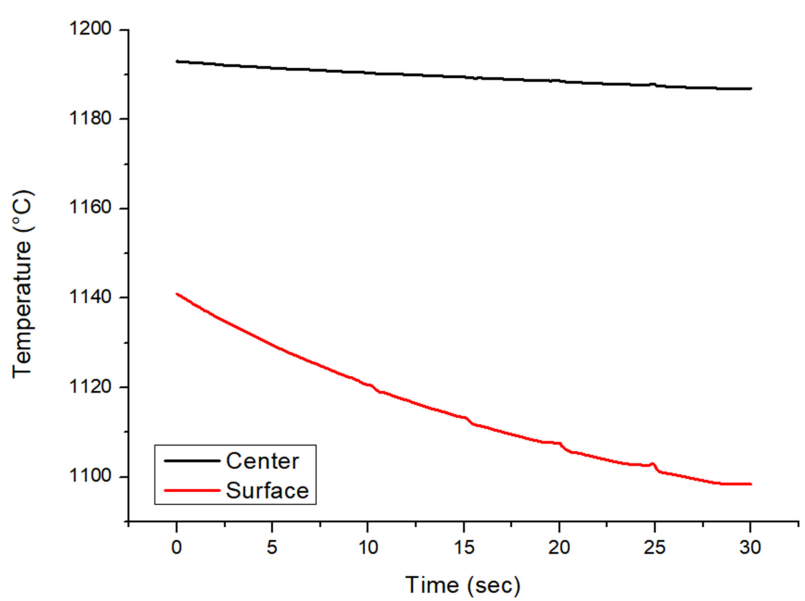

Fig. 6. Graph of cooling simulation with respect to time

\subsection{Slab heater cover effect}

To study the effect of the slab heater cover, the simulation results of the temperature with and without slab heater during cooling were compared as shown in Fig. 7. The differences in center temperatures with and without cover cases were very small, within $3{ }^{\circ} \mathrm{C}$, but the surface temperature differences were larger. The center temperature was cooled by conduction, but the surface temperature was chilled by convection and radiation. The amount of cooling by conduction is governed by the temperature difference between the center and the surface, while heat transfer by convection and radiation are determined the temperature difference between the atmosphere with room temperature and the surface. Therefore, there was no significant difference in the center temperature after cooling regardless

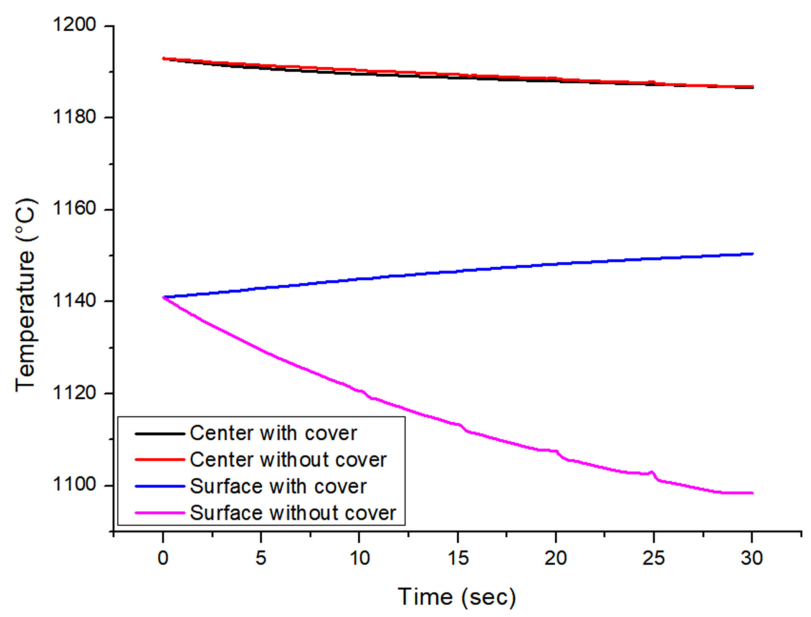

Fig. 7. Temperature with respect to time during cooling simulation of the presence of the cover. In the absence of a cover, the temperature differences between the surface and atmosphere remained almost constant because the atmosphere was maintained at a constant temperature (room temperature). However, in the opposite case, the bottom surface of the cover was heated by the slab surface, so heat fluxes were decreased. Therefore, the slab heater cover is effect on the reduce of temperature gradient of the slab.

\subsection{Simulation results}

Because of the characteristics of the CEM process, a slab can be produced in an infinite length. However, it is impossible to deal with the infinite length of the slab in a simulation. Therefore, it would be useful to determine the moving distance of a slab with an unchanging average temperature. Figure 8 and 9 show the simulation conditions and results of temperature distribution, respectively. Figure 10 shows the average temperature of the slab with respect to the slab moving distance.

The initial temperature of the cover and atmosphere were set to room temperature. The dominant heat transfer method was radiation from the heater to the slab due to the slab's high temperature compared to its surroundings. Heat transfer caused by natural convection also occurred. The coefficient of natural convection was set to $5 \mathrm{~W} / \mathrm{m}^{2} \mathrm{~K}$. The slab moved
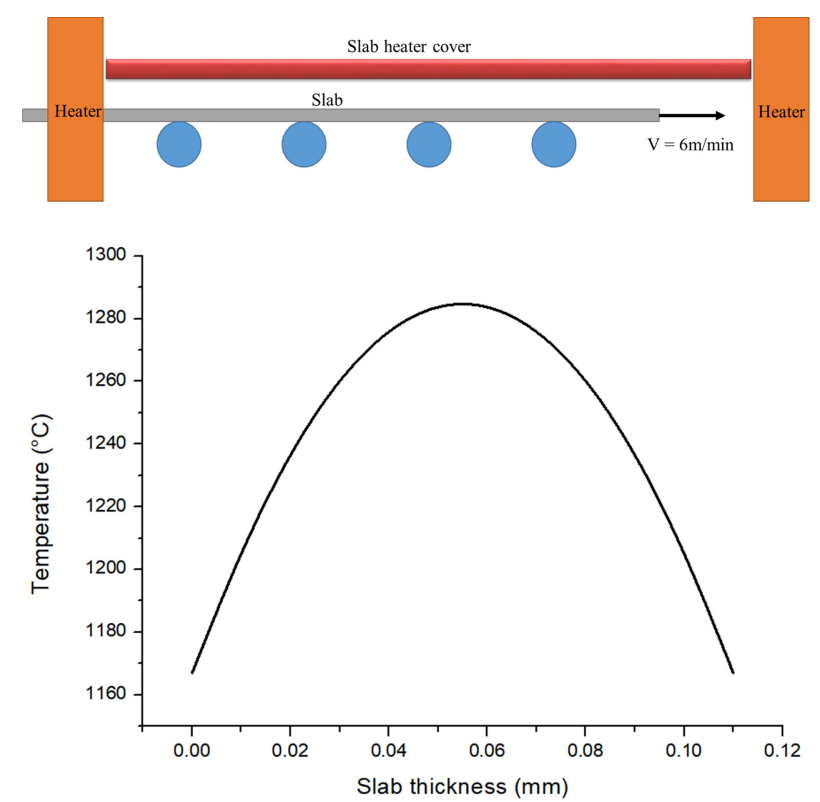

Fig. 8. Simulation conditions 


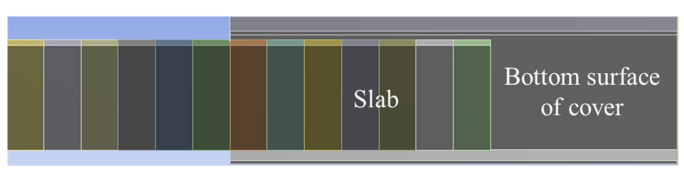

(a)

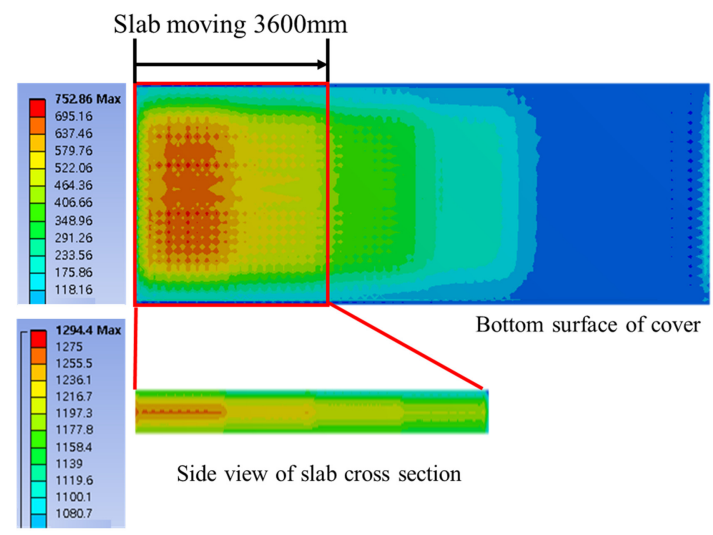

(b)

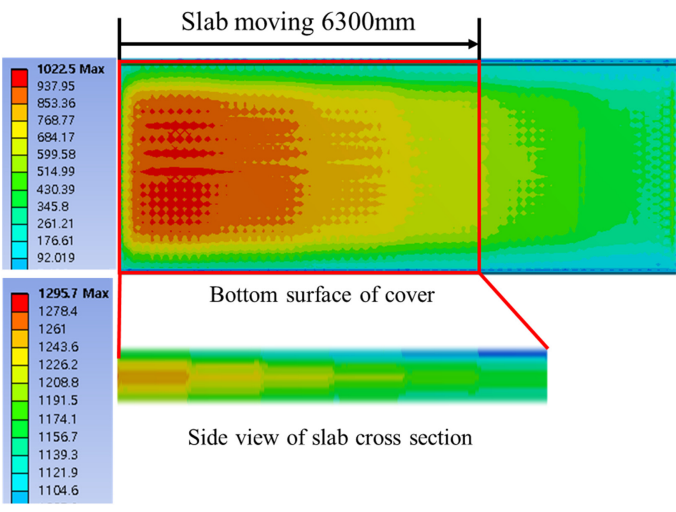

(c)

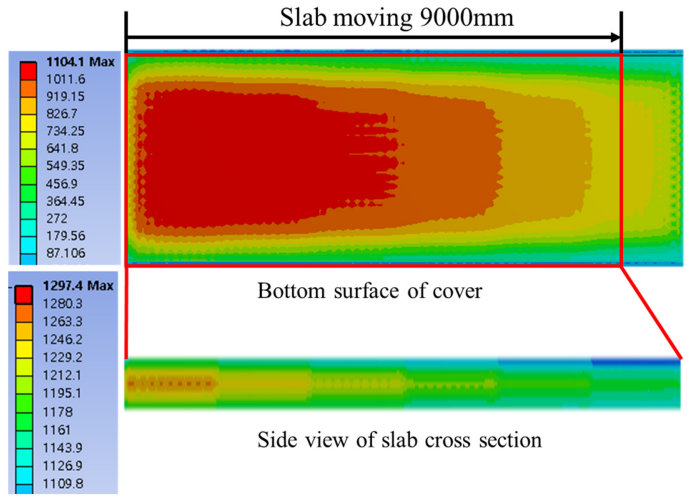

(d)

Fig. 9. (a) Structure of cover and slab, and temperature distribution of cover bottom surface and slab with (b) $3600 \mathrm{~mm}$, (c) $6300 \mathrm{~mm}$, and (d) $9000 \mathrm{~mm}$ moving, respectively.

at $6 \mathrm{~m} / \mathrm{min}$, which was the optimal speed for the new layout as determined by POSCO [3].

Initially, a slab with the temperature distribution defined in Fig. 8 was inserted into the cover at room temperature and the bottom of the cover was gradually heated. At this time, a slab that was not inserted into the cover was kept at the initial temperature distribution, and conduction occurred inside the slab. When the temperature of the bottom of the cover was increased above a certain level, the conduction effect inside the slab became larger than the heat transfers between slab and cover. Thus, the average slab temperature was moderately increased. The increased rates decreased and became zero when the slab moving distance reached $9000 \mathrm{~mm}$. In other words, steady-state simulations can be performed after the saturation point.

Based on the above results, thermal analysis of slab temperature distribution was conducted to investigate the efficiency of the cover during the CEM process shown in

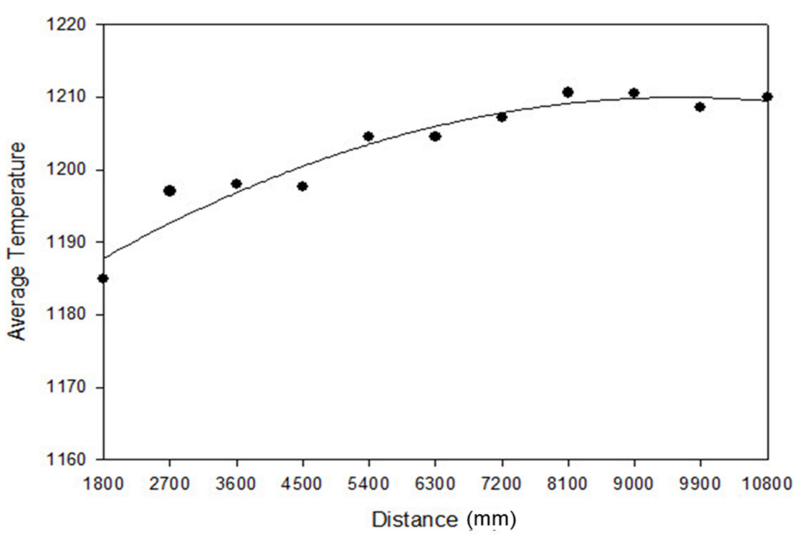

Fig. 10. Slab average temperature with respect to slab moving distance

Fig. 11.

The rate of temperature drop decreased by more than $50 \%$ when the slab heater cover was used. Furthermore, the temperature distribution was more uniformed, which contributed to improving the quality of the slab. 


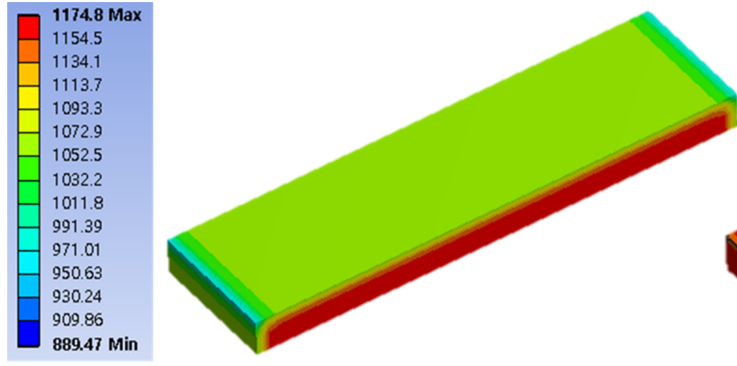

(a)

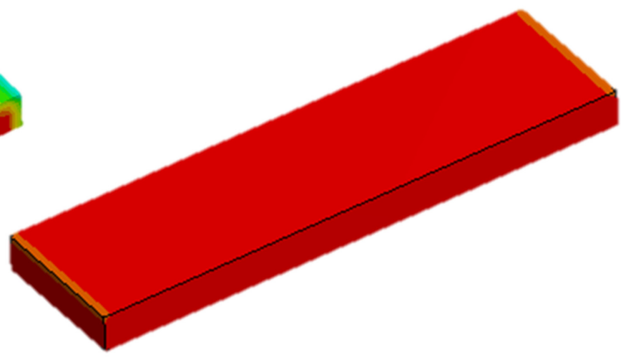

(b)

Fig. 11. Slab temperature distribution during CEM process (a) without cover, (b) with cover
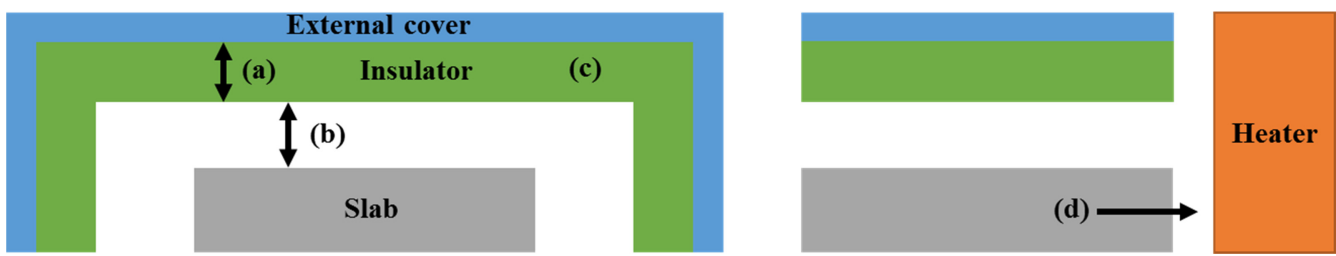

Fig. 12. Sensitivity parameters (a) insulator thickness, (b) gap between slab and insulator, (c) insulator material properties, (d) slab speed

\subsection{Sensitivity analysis of the slab heater cover}

Sensitivity analysis is a quantification method to indicate the influence between the input and output parameters. Through sensitivity analysis, output parameters such as slab temperature, thermal stress, thermal strain, and total deformation were compared to design the slab heater cover. The sensitivity parameters were normalized to derive the correlation of variables regardless of the magnitude of values. Sensitivity is defined in equation 5 [19].

$$
\text { Sensitivity (\%) } \equiv \text { Output Change (\%) / Input Change(\%) }
$$

For the sensitivity analysis, the input parameters were varied $\pm 30 \%$ and the subsequent changes in the output parameters were examined. Figure 12 shows the input parameters for the sensitivity analysis. The sensitivity results are summarized in Fig. 13 and Table 4.

With respect to slab temperature, the slab speed was the most dominant factor. When the slab moved faster, the heat transfer rate between the slab and other materials, such as the insulator, decreased. The material properties of the insulator were also an important factor.

$$
Q=c \rho V \Delta T
$$

Heat transfer can be calculated using equation 6 , where $Q$

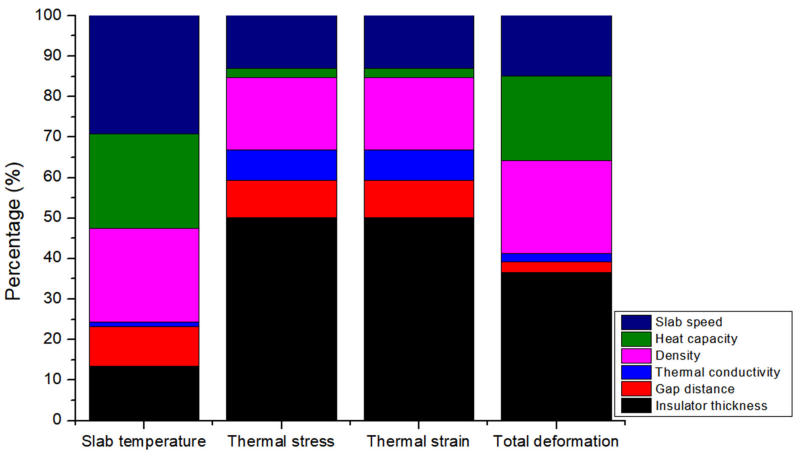

Fig. 13. Sensitivity analysis results for each parameters

Table 4. Sensitivity results

\begin{tabular}{ccccc}
\hline $\begin{array}{c}\text { Input } \\
\text { parameters }\end{array}$ & $\begin{array}{c}\text { Slab } \\
\text { temperature }\end{array}$ & $\begin{array}{c}\text { Thermal } \\
\text { stress }\end{array}$ & $\begin{array}{c}\text { Thermal } \\
\text { strain }\end{array}$ & $\begin{array}{c}\text { Vertical } \\
\text { direction } \\
\text { deformation }\end{array}$ \\
\hline $\begin{array}{c}\text { Insulator } \\
\text { thickness }\end{array}$ & 0.135 & 0.502 & 0.502 & 0.366 \\
\hline \begin{tabular}{c} 
Gap distance \\
\hline $\begin{array}{c}\text { Thermal } \\
\text { conductivity }\end{array}$
\end{tabular} & 0.098 & 0.091 & 0.091 & 0.027 \\
\hline Density & 0.231 & 0.075 & 0.075 & 0.020 \\
\hline Specific heat & 0.233 & 0.023 & 0.023 & 0.209 \\
\hline Slab speed & 0.292 & 0.129 & 0.129 & 0.149 \\
\hline
\end{tabular}

is the heat transfer, $c$ is the specific heat, $r$ is the density, $V$ is the volume of the substance, and $\Delta T$ is the temperature gradient. The heat transfer is proportional to the density and 
specific heat.

Specific heat is one of the most sensitive material parameters. Material properties affect the radiation and conduction, so they affect the temperature changes of the insulator in response to the effect of the slab heater.

In the aspect of kinetics, thermal stress was most affected by insulator thickness. A high thermal stress could cause cracks and distortions in the insulator and body of the slab heater cover [20]. Density and slab speed also affect the kinetic parameters because the temperature difference between the slab and insulator cover increases as either parameter increases.

The slab heater is composed of an insulator, a cover, and a slab, which are linear elastic materials. Therefore, the stress and strain followed the Hooke's law. Thus, the results of the sensitivity analysis for the thermal stress and the strain are the same. Finally, deformation in the vertical direction was most affected by the insulator thickness because the temperature gradient increased as the insulator thickness increased. In addition, a large temperature gradient caused an increase in thermal stress and strain, so the deformation in the vertical direction increased. The material properties of the cover (density and heat capacity) were also important parameters.

\section{CONCLUSION}

Use of a slab heater cover was effective in reducing the temperature drop in the slab during CEM. This paper presented a sensitivity analysis of the slab heater cover using FEM methods to identify the parameters that are important in designing the cover. Prior to the sensitivity analysis, simulation verification was performed by comparing experimental and simulation results. The results verified the efficiency of the slab heater cover in reducing the temperature drop during the CEM process was verified. Temperature was most affected by material properties such as density, heat capacity and slab speed. Kinetics and kinematics were most affected by the insulator thickness; density was also important. These simulation results for the slab heater cover provide information about the factors that are important in the design of a slab heater to increase efficiency. This work contributes to understanding of the
CEM process, but can also be applied to other hightemperature steel-production processes such as rolling and casting.

\section{ACKNOWLEDGEMENT}

This work was supported by POSCO.

\section{REFERENCES}

1. D. E. Humphreys, J. D. Madill, V. Ludlow, D. Stejwart, S. G. Thornton, and A. S. Normanton, 1st European Conference on Continuous Casting, P.1529, Florence, Italy (1991).

2. C. McCulloch, A. Kumar, E. B. Hawbolt, and I. V. Samarasekera, Steel Product-Process Integration (ed. J. D. Boyd), p.216, CIM, Halifax (1989).

3. I. Lee, 15th International Conference on Advances in Materials \& Processing Technologies Conference 2012 (AMPT 2012), Wollongong, Australia (2012).

4. Y. Kong, D. Chen, Q. Liu, H. Chen, and M. Long, Steel Res. Int. 89, 1800091 (2018).

5. J. K. Brimacombe and K. Sorimachi, Metall. Mater.Trans. $B$ 8, 489 (1977).

6. H. F. Shen, R. A. Hardin, R. Mackenzie, and C. Beckermann, J. Mater. Sci. Technol. 18, 311 (2002).

7. T. Kato, Y. Ito, M. Kawamoto, A. Yamanaka, and T. Watanabe, ISIJ Int. 43, 1742 (2003).

8. H. M. Wang, G. R. Li, Y. C. Lei, Y. T. Zhao, Q. X. Dai, and J. J. Wang, ISIJ Int. 45, 1291 (2005).

9. J. Sengupta, B. G. Thomas, and M. A. Wells, Metall. Mater. Trans. A 36, 187 (2005).

10. X. Y. Wang, Q. Liu, B. Wang, X. Wang, J. S. Qing, Z. G. Hu, and Y. H. Sun, Ironmak. Steelmak. 38, 552 (2011).

11. H. Ma, Q. Wang, Y. G. Li, Y. J. Lu, and S. P. He, Metal. Int. 17, 30 (2012).

12. D. Duly, J. G. Lenard, and J. A. Schey, J. Mater. Process. Tech. 75, 143 (1998).

13. L. M. Galantucci and L. Tricarico, J. Mater. Process. Tech. 92, 494 (1999).

14. J.-H. Lee, S.-J. Park, J. Moon, J.-Y. Kang, J. Y. Park, T.-H. Lee, and K. M. Cho, Korean J. Met. Mater. 55, 363 (2017).

15. J. Y. Park, S. J. Park, J. H. Lee, J. Moon, T. H. Lee, K. J. Jeong, and J. H. Shin, Korean J. Met. Mater. 55, 12 (2017).

16. R. Siegal and J. R. Howell. Thermal Radiation Heat Transfer. 2nd Ed. pp 6-12, Hemisphere Publishing 
Corporation, New York (1981).

17. A. Laasraoui and J. J. Jonas, ISIJ Int. 31, 95 (1991).

18. Ansys. "12.0 Theory Guide." Ansys Inc 5 (2009).

19. J. H. Jeong and S. J. Park, Comp. Mater. Sci. 100, 21 (2015).
20. E. Gadalińska, A. Baczmański, S. Wroński, P. Kot, M. Wroński, M. Wróbel, and K. Wierzbanowski, Met. Mater. Int. 135, 24 (2018). 